\title{
Social networks moderate the association between physical fitness and cognitive function among community-dwelling older adults: a population-based study
}

\author{
Hui Foh Foong ${ }^{1}$, Rahimah Ibrahim ${ }^{1,2^{*}}$, Tengku Aizan Hamid ${ }^{1}$ and Sharifah Azizah Haron ${ }^{3}$
}

\begin{abstract}
Background: Physical fitness declines with age. Low levels of physical fitness appear to be a risk factor of cognitive impairment. Literature elucidates social networking as a potential moderator for the relationship between physical fitness and cognitive impairment. Present study aimed to examine the relationship between physical fitness and cognitive function among community-dwelling older Malaysians, and if social network moderates said relationship.

Methods: Data of 2322 representative community-dwelling older adults were obtained from the first wave of the "Longitudinal Study on Neuroprotective Model for Healthy Longevity" national survey. Cognitive function, physical fitness and social network was assessed through Malay-version of Mini-Mental State Examination, 2-min step test and Lubben Social Network Scale-6 respectively. Moderated hierarchical multiple regression was employed to investigate if social networks moderate the relationship between physical fitness and cognitive function.

Results: A positive association between physical fitness and cognitive function were found upon controlling for covariates. Moderated hierarchical multiple regression revealed social networks to be a moderator of the association between physical fitness and cognitive function. When physical fitness was low, those with small social network revealed lowest cognitive function.

Conclusions: Social networks moderated the relationship between physical fitness and cognitive function as older adults with low levels of physical fitness and small social networks revealed lowest cognitive function. Therefore, community support or peer-based interventions among physically unfit older adults should be implemented to promote cognitive function.
\end{abstract}

Keywords: Cognitive function, Physical fitness, Social isolation, Social network

\section{Background}

Malaysia, like several other countries, is currently undergoing rapid population ageing. In 2016, 6.0\% (1.9 million) of Malaysians were older adults aged 65 and above [1].

\footnotetext{
*Correspondence: imahibrahim@upm.edu.my

${ }^{1}$ Malaysian Research Institute on Ageing (MyAgeing ${ }^{\mathrm{TM}}$ ), Universiti Putra Malaysia, 43400 Serdang, Selangor, Malaysia

Full list of author information is available at the end of the article
}

However, the number is set to rise to $15 \%$ (5.6 million) by 2035 , at which point Malaysia will attain ageing nation status [2]. As such, prevalence of cognitive impairment is also expected to increase as most cognitive function domains tend to deteriorate with age, especially among women due to limited later life resources [3]. A recent study based on the Montreal's Cognitive Assessment cut-off point of $22 / 23$ found prevalence of cognitive 
impairment among Malaysian community-dwelling older adults aged 60 and above to be $75.2 \%$ [4].

Physical fitness refers to the body's capacity to function effectively towards a healthy state, aside from its ability to perform daily and occupational activities. It has been established that physical fitness tends to decline with age. Poor physical fitness has also been highly correlated to older person morbidity and mortality. However, frequent exercise could help maintain physical fitness [5]. Physical fitness is an important determinant of cognitive function in old age, as evidenced by a recent study that found positive association between cognitive function and physical fitness in adults aged 55 and above [6]. Moreover, physical fitness was found to promote cognitive function among older patients with mild cognitive impairment [7].

Social networks, on the other hand refer to the web of social interactions and relationships, which apparently improves life satisfaction among older adults [8]. Older adults with limited social networks were at risk of social isolation [9]. In fact, approximately $49.8 \%$ of older Malaysians were at risk for social isolation [10], with significant associations found among women, non-Malays, nonhomeowners, urban-dwellers, those living within larger household sizes, those with lesser number of siblings and those with lower perceived health status [10]. The role of social networks as a protective factor in development of cognitive impairment among older adults has been widely reported [11].

There are several grounds as to why social networks might act as a moderator in this study. Primarily, past literature has observed differing cognitive capacity and physical fitness levels among older adults with differing social network status. For instance, cognitive function was found to be higher among older adults with wider social network [12, 13]. Furthermore, a recent study discovered that social isolation among older adults were associated with daily physical inactivity [14], with reduced physical activity being the main contributor towards poor physical fitness among older adults [15]. In addition, decline in social networking among older adults were also attributed to gradual irreversible relinquishing of social roles, relegation of previous job roles, straying current social relationships, and collapse of extended family due to increasing age and retirement [16]. Considering the aforementioned reasons, this study aimed to examine the moderating role of social networks in the association between physical fitness and cognitive function to better understand the nature of interaction between social networks and physical fitness in predicting cognitive function. Three hypotheses were formulated in accordance to the study's objective; $\mathrm{H}_{\mathrm{A}}$ : Physical fitness was positively associated with cognitive function, $\mathrm{H}_{\mathrm{A}}$ 2: Social networks were positively associated with cognitive function, and $\mathrm{H}_{\mathrm{A}}$ 3: Social networks moderated the association between physical fitness and cognitive function.

\section{Methods \\ Study design, participants, and procedure}

The study involved secondary analysis of data sourced from Wave 1 (2012-13) of the "Longitudinal Study on Neuroprotective Model for Healthy Longevity" in Malaysia. Design of the study was cross-sectional, where data was collected from community-dwelling older persons aged 60 years or above through face to face, intervieweradministered surveys. Details of the study which includes sampling and research design have been formerly presented [17]. This survey utilized multi-stage stratified random sampling technique, beginning with random selection of a state from each zone in Peninsular Malaysia. After, 35 census clusters from each state were sampled, where 20 living quarters were selected from each census circle cluster. All respondents from the selected living quarters were randomly interviewed. Response rate obtained was $87.8 \%$. Publications via similar methodology have been formerly presented [18]. The original dataset consisted of 2322 respondents and the present study involved all of them in the analysis without any exclusion criteria. The original study covered a wide range of variables; however, this paper only focused on cognitive function, physical fitness and social networks as per study interest. Authors established that all methods and procedures were performed in accordance with relevant guidelines and regulations.

\section{Measures}

\section{Cognitive function (dependent variable)}

Cognitive function was evaluated through the Malayversion of Mini-Mental State Examination (MMSE) [19, 20]. The instrument included cognitive domains of visuospatial skills, language, concentration, working memory, memory recall, and orientation, assessed through 11 task items. Maximum obtainable score was 30, where higher score indicated higher cognitive ability. Cut-off point of 21/22 was apt for identifying older Malaysians with cognitive impairment [19]. MMSE scores served as a numeric discontinuous variable (score: $0-30$ ) and as a categorical variable (cognitive impairment vs without cognitive impairment) for further analyses.

\section{Physical fitness (independent variable)}

The 2-min step was used to assess physical fitness [21]. Test validity have been formerly presented [22]. Respondents were first instructed to stand next to a wall, where the iliac crest and patella heights were measured and marked, respectively. After, a piece of tape was placed in 
between both marks. Respondents were then instructed to step in place by raising each knee towards the tape as many times as possible within 2 min. Physical fitness scores were calculated based on the number of times the right knee reached the required height. The cut-off point of scores was based on a functional fitness normative study among community-dwelling older adults by Rikli and Jones, with scores below 65 were associated with lower levels of functional ability [21]. The cut-off point was apt to identify the prevalence of older adults with lower levels of physical fitness [21]. Scores were also divided into two categories of fitness levels - lower levels $(<65)$ and higher levels $(\geq 65)$. The 2-min step test scores served as a numeric discontinuous variable (number of times) and as a categorical variable (low fitness level vs high fitness level) for further analysis.

\section{Social networks (moderator)}

Social network was measured via Lubben Social Network Scale-6 [9]. This validated instrument evaluates social isolation among older adults by quantifying frequencies of social contact with friends and family members, as well as perceived social support obtained from stated sources. Obtainable scores ranged from 0 to 30, where higher scores indicated a larger social network. The cutoff point of 12 and lower were indicative of risk and prevalence for social isolation among older adults [9]. Social network scores obtained served as continuous and categorical variable for further analysis.

\section{Covariates}

The 4-step moderated hierarchical multiple linear regression was utilised to control effects of demographic variables like age, sex, year(s) of education, marital status, employment status, household income, ethnicity, comorbidity status, and living arrangement. Categorical variables were dummy-coded; sex $($ male $=0$, female $=1)$, marital status (married $=0$, not married $=1$ ), employment status (currently employed $=0$, currently not employed $=1$ ), living arrangement (living with others $=0$, living alone $=1$ ), multimorbidity status (multimorbidity $=1$, no multimorbidity $=0$ ], and ethnicity (Chinese and Indian =0, Malay=1). Age, year(s) of education, and household income were measured in the continuous form.

\section{Statistical analysis}

Statistical analyses were conducted via SPSS software (v23.0; IBM Corporation, Armonk, NY, USA). First, chisquare statistic was performed when the approach of the variables was categorical. Then, Pearson's correlation, independent sample $t$-test, and moderated hierarchical multiple linear regression were performed when the approach of the variables was numerical. Associations between participant characteristics with key variables (i.e., physical fitness, cognitive function, and social networks) were first evaluated via chi-square statistics. Pearson's correlation was then employed to observe bivariate correlations among the aforementioned key variables. Besides, independent sample $t$-test was used to observe differences in cognitive functions and social network between different physical fitness levels (i.e., high versus low). After that, a moderated hierarchical multiple linear regression was conducted to examine the moderating role of social network in the link between physical fitness and cognitive function. Control variables (i.e., sociodemographic and economic variables) were first added into the primary model. The independent variable (physical fitness) and moderator (social networks) were then entered into the secondary and tertiary model respectively. The final model involved addition of the interaction term (physical fitness $\times$ social networks). Significant $R^{2}$ change indicated significant moderating effects. If the interaction term (physical fitness $\times$ social networks) is significant in the final model, the interaction graph is plotted to visualize the relationship between physical fitness and cognitive function based on three levels of social networks; -1 standard deviation (SD) for small, 0 SD for moderate, and +1 SD for large social networks. Continuous variables were centred prior to the regression analysis to prevent multicollinearity. VIF values obtained ranged from 1.010 to 1.510 , less than 10 , indicating nonpresence of multicollinearity [23]. Statistical significance was set at two-sided $p$-value $<0.05$.

\section{Results}

\section{Background information of the sample}

Table 1 depicts participants' characteristics as well as distribution of respondents and study variables by levels of physical fitness level. The present study involved 2322 community-dwelling older adults, $51.9 \%$ of which were younger than 69 years old. Sex distribution was almost equal, where $52.2 \%$ of the respondents were women. Most were ethnic Malays (63.2\%), married (60.9\%), and living with others $(89.3 \%)$. In terms of socioeconomic characteristics, majority received less than 7 years of education $(76.4 \%)$, were not currently working (77.3\%) and were from lower income group (91.1\%). A total of $50.4 \%$ had a comorbidity status of more than one chronic condition. Demographic details have been formerly published [24].

Chi square statistic found significant associations between physical fitness and sex $\left(\chi^{2}=88.82, p<0.001\right)$, marital status $\left(\chi^{2}=35.56, p<0.001\right)$, employment status $\left(x^{2}=7.58, \quad p=0.006\right)$, ethnicity $\left(\chi^{2}=34.96\right.$, $p<0.001)$, cognitive function $\left(x^{2}=39.64, p<0.001\right)$, 
Table 1 Respondents' characteristics and distribution of study variables by levels of physical fitness

\begin{tabular}{|c|c|c|c|c|}
\hline & \multicolumn{4}{|l|}{ Physical fitness } \\
\hline & $\begin{array}{l}\text { Higher levels of physical } \\
\text { fitness ( } \geq 65 \text { steps) }\end{array}$ & $\begin{array}{l}\text { Lower levels of physical } \\
\text { fitness (< } 65 \text { steps) }\end{array}$ & $\begin{array}{l}\text { Chi-square statistic or } \\
t \text {-value }\end{array}$ & $P$-value \\
\hline & $\begin{array}{l}n(\%) \text { or mean } \pm \text { standard } \\
\text { deviation }\end{array}$ & $\begin{array}{l}n(\%) \text { or mean } \pm \text { standard } \\
\text { deviation }\end{array}$ & & \\
\hline \multicolumn{5}{|l|}{ Sex } \\
\hline Men & $599(56.5)$ & $461(43.5)$ & $88.82^{\mathrm{a}}$ & $<0.001^{c}$ \\
\hline Women & $419(36.5)$ & $729(63.5)$ & & \\
\hline \multicolumn{5}{|l|}{ Marital status } \\
\hline Married & $762(50.4)$ & $750(49.6)$ & $35.56^{\mathrm{a}}$ & $<0.001^{c}$ \\
\hline Not married & $256(36.8)$ & $440(63.2)$ & & \\
\hline \multicolumn{5}{|l|}{ Employment status } \\
\hline Currently working & $256(51.4)$ & $242(48.6)$ & $7.58^{\mathrm{a}}$ & $0.006^{c}$ \\
\hline Currently not working & $741(44.4)$ & $928(55.6)$ & & \\
\hline \multicolumn{5}{|l|}{ Living arrangement } \\
\hline Living with others & $911(46.1)$ & $1067(53.9)$ & $0.02^{\mathrm{a}}$ & $0.893^{c}$ \\
\hline Living alone & $107(46.5)$ & $123(53.5)$ & & \\
\hline \multicolumn{5}{|l|}{ Multimorbidity status } \\
\hline No multimorbidity & $527(47.9)$ & $574(52.1)$ & $2.74^{\mathrm{a}}$ & $0.098^{c}$ \\
\hline Multimorbidity & $491(44.4)$ & $616(55.6)$ & & \\
\hline \multicolumn{5}{|l|}{ Ethnicity } \\
\hline Malay & $570(41.3)$ & $811(58.7)$ & $34.96^{\mathrm{a}}$ & $<0.001^{c}$ \\
\hline Non-Malay & $446(54.3)$ & $376(45.7)$ & & \\
\hline \multicolumn{5}{|l|}{ Cognitive function } \\
\hline No cognitive impairment & $752(50.6)$ & $733(49.4)$ & $39.64^{\mathrm{a}}$ & $<0.001^{c}$ \\
\hline Cognitive impairment & $255(36.3)$ & $448(63.7)$ & & \\
\hline \multicolumn{5}{|l|}{ Social networks } \\
\hline No social isolation & $578(48.1)$ & $623(51.9)$ & $5.33^{\mathrm{a}}$ & $0.021^{c}$ \\
\hline At risk of social isolation & $416(43.2)$ & $548(56.8)$ & & \\
\hline Age & $68.1 \pm 5.58$ & $69.5 \pm 6.48$ & $-5.88^{b}$ & $<0.001^{d}$ \\
\hline Year(s) of education & $6.1 \pm 4.12$ & $4.4 \pm 3.69$ & $10.52^{b}$ & $<0.001^{d}$ \\
\hline Household income & $1178.9 \pm 1064.87$ & $915.8 \pm 940.54$ & $5.97^{b}$ & $<0.001^{d}$ \\
\hline
\end{tabular}

${ }^{a}$ Chi-square statistic; ${ }^{b}$-value; ${ }^{c}$ Chi-square test; ${ }^{d}$ Independent sample $t$-test

and social network $\left(\chi^{2}=5.33, p=0.021\right)$, respectively. Lower levels of physical fitness were prevalent among older adults whom were women, ethnic Malays, nonmarried, not currently working, cognitively impaired, and at risk of social isolation. Independent sample $t$-test reported significant differences in age $(t=-5.88$, $p<0.001)$, year(s) of education $(t=10.52, p<0.001)$, and household income $(t=5.97, p<0.001)$ across different levels of physical fitness. Those within the lower levels of physical fitness had significantly lower education level, lower household income and older age (see Table 1). The use of the aforementioned cut-off points found prevalence of cognitive impairment, lower levels of physical fitness, and social isolation was 33.1, 54.1, and $40.0 \%$, respectively.

\section{Correlations among main study variables and differences} of cognitive function and social network by physical fitness level

The minimum, maximum, mean, and standard deviation of physical fitness, cognitive function, and social network are as reported in Table 2. Pearson's correlation analysis stipulated a positive correlation between cognitive function, physical fitness $(r=0.17, p<0.001)$ and social networks $(r=0.08, p<0.001)$. Results also revealed physical fitness to be significantly and positively correlated with social networks $(r=0.10, p<0.001)$ (see Table 1$)$.

Independent sample $t$-test was used to compare cognitive function and social network among respondents from different physical fitness groups. Older adults with lower physical fitness levels reported lower cognitive 
Table 2 Correlations among cognitive function, physical fitness, and social networks

\begin{tabular}{|c|c|c|c|c|c|c|c|}
\hline \multirow[t]{2}{*}{ Variable } & \multirow[t]{2}{*}{ Minimum } & \multirow[t]{2}{*}{ Maximum } & \multirow[t]{2}{*}{ Mean } & \multirow[t]{2}{*}{ SD } & \multicolumn{3}{|c|}{ Correlation coefficient $(r)$} \\
\hline & & & & & Cognitive function & Physical fitness & $\begin{array}{l}\text { Social } \\
\text { networks }\end{array}$ \\
\hline Cognitive function & 0 & 30 & 22.6 & 5.03 & 1 & & \\
\hline Physical fitness & 0 & 142 & 60.5 & 25.97 & $0.17^{* * *}$ & 1 & \\
\hline Social networks & 0 & 30 & 13.7 & 6.55 & $0.08^{* * *}$ & $0.10^{* * *}$ & 1 \\
\hline
\end{tabular}

$S D$ Standard deviation

*** $p<0.001$

function in comparison to older adults with higher physical fitness levels $(t=6.714, p<0.001)$. Similarly, those with higher levels of physical fitness also had significantly larger social networks $(t=3.090, p<0.002)$ (see Table 3$)$.

\section{Moderating effects of social networks on the association between physical fitness and cognitive function}

Four-step moderated hierarchical multiple regression was employed to examine the moderating role of social networks in the link between physical fitness and cognitive function. Confounding variables entered during the first model revealed a significant model $[\mathrm{F}(9,2040)=39.345$, $\left.p<0.001, R^{2}=0.148\right]$. Sociodemographic and economic characteristics explained $14.8 \%$ of the variance in cognitive function. As shown in Table 4, younger age $(\beta=-0.11, p<0.001)$ and higher educational levels $(\beta=0.27, p<0.001)$ were associated with higher levels of cognitive function. Lower levels of cognitive function were also associated with women $(\beta=-0.07, p=0.008)$ and ethnic Malays $(\beta=-0.15, p<0.001)$.

The independent variable, physical fitness, was added in the secondary model, its addition significantly increasing model fit $\left[\mathrm{F}(1,2039)=35.969, p<0.001, R^{2}=0.150\right.$, $\left.\Delta R^{2}=0.002\right]$. As shown in Table 4 , physical fitness was found to be positively associated with cognitive function $(\beta=0.05, p=0.027)$. The addition of the moderator, social networks in the third model also significantly increased model fit $[\mathrm{F}(1,2038)=33.071, p<0.001$, $\left.R^{2}=0.151, \Delta R^{2}=0.001\right]$. However, this study failed to establish a relationship between social networks and cognitive function, upon controlling for potential confounding factors $(\beta=0.04, p=0.057)$ (see Table 4$)$.

The interaction term (physical fitness $\times$ social networks) was added into the last model, where a significant increase of model fit was observed $[\mathrm{F}(1,2037)=30.908$, $\left.p<0.001, R^{2}=0.154, \Delta R^{2}=0.003\right]$. F change obtained was significant at $p=0.013$ upon addition of the interaction term. As reported in Table 4, the interaction term was statistically significant $(\beta=-0.17, p=0.013)$, hence indicating the moderating effect of social networks on the link between physical fitness and cognitive function. The relationship between physical fitness and cognitive function was plotted for small ( -1 standard deviation), moderate (0 standard deviation) and large social networks ( +1 standard deviation) as shown in Fig. 1 to further observe the relationship at differing levels of social networks. As illustrated, older adults with low levels of physical fitness and small social networks revealed lowest cognitive function. Conversely, those with high levels of physical fitness and small social networks revealed highest cognitive function.

\section{Discussion}

Findings from the study concurs that a positive correlation existed between physical fitness and cognitive function. However, there was no proof of an association between social networks and cognitive function after controlling for possible confounders, aside from the discovery that social networks moderated the association between physical fitness and cognitive function. $\mathrm{H}_{\mathrm{A}} 1$ was supported when the study revealed higher physical

Table 3 Comparisons of cognitive function and social networks by different levels of physical fitness

\begin{tabular}{|c|c|c|c|c|}
\hline Variable & $\begin{array}{l}\text { Higher levels of physical fitness }(\geq \\
65 \text { steps) } \\
\text { (mean } \pm \text { SD) }\end{array}$ & $\begin{array}{l}\text { Lower levels of physical fitness (< } \\
65 \text { steps) } \\
\text { (mean } \pm \text { SD) }\end{array}$ & $t$-value & $P$-value \\
\hline Cognitive function & $23.5 \pm 4.64$ & $22.1 \pm 4.92$ & 6.714 & $<0.001$ \\
\hline Social networks & $14.2 \pm 6.56$ & $13.3 \pm 6.54$ & 3.090 & 0.002 \\
\hline
\end{tabular}

Significance of bold values $=p<0.05$

SD Standard deviation 


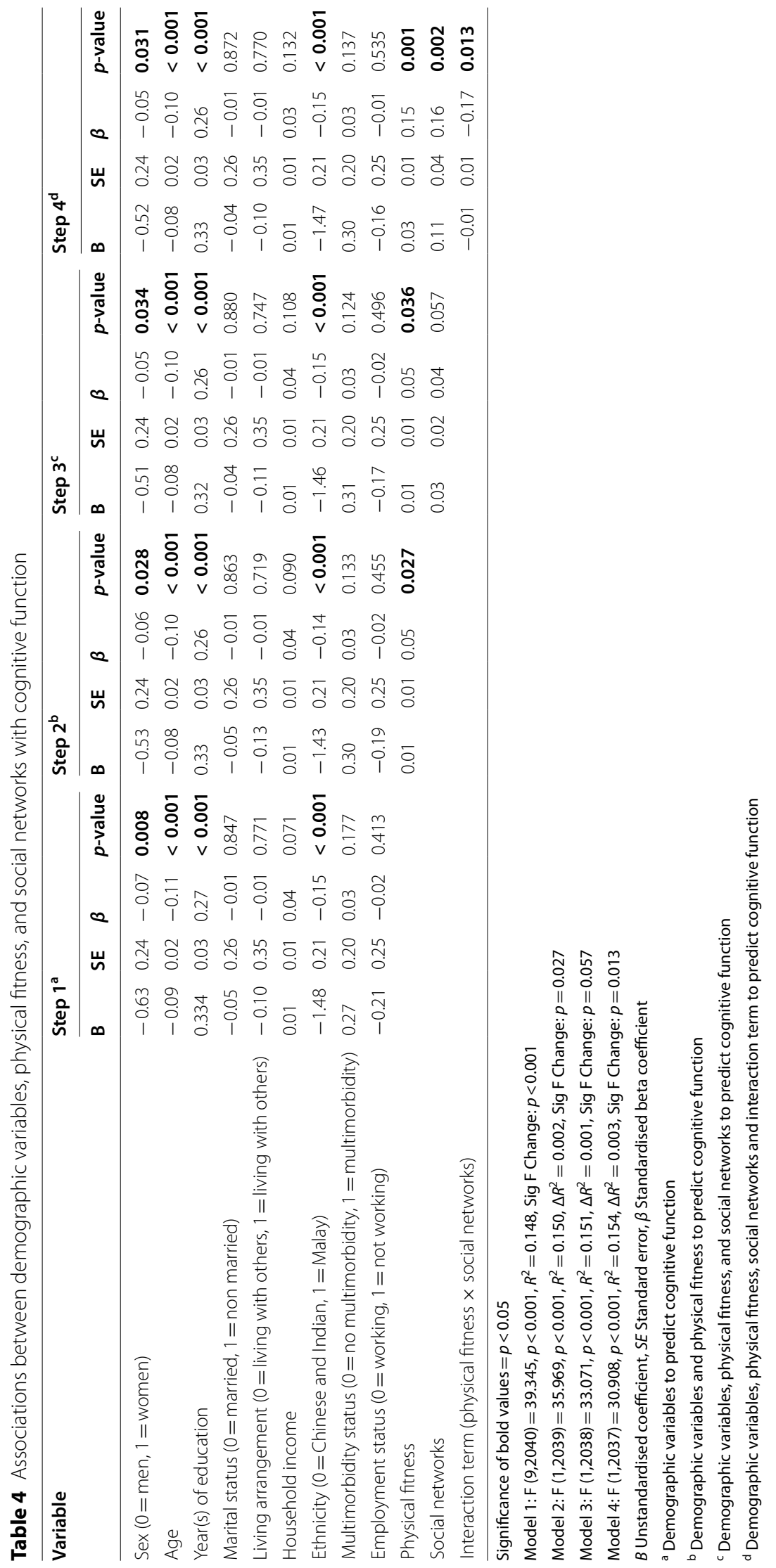




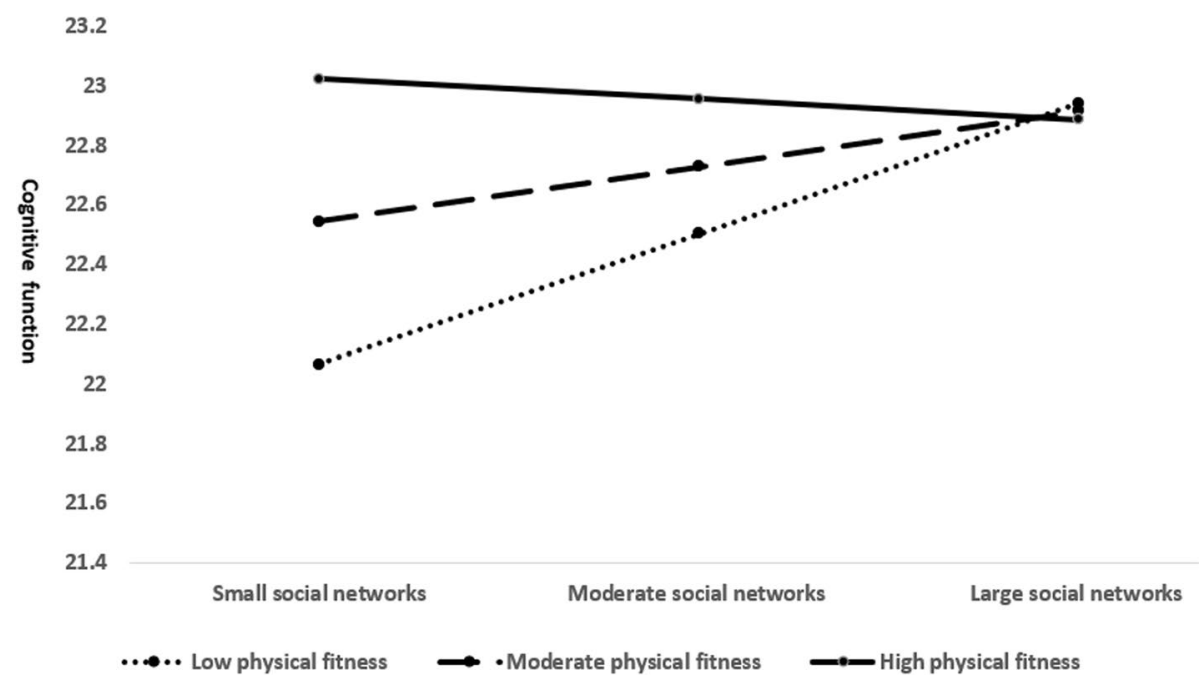

Fig. 1 Interaction effect between physical fitness and social networks on cognitive function

fitness levels were associated with higher cognitive function. Consistent with these findings are results from the Australia Stroke Prevention Study. The study found higher physical fitness in older persons to be associated with higher global cognitive function scores, memory, executive function, and motor abilities [25]. Several recent studies have also shown that physical activities promotes cognitive vitality [26, 27], Daimiel and colleagues argued based on their investigation involving 6874 participants in Spain, that physical fitness, but not physical activity, was associated with a higher cognitive function [28]. They found that physical fitness correlated with higher MMSE language domain score and total score [28]. Precise mechanism between physical fitness and cognitive function in older adults remains elusive. But proper cerebral perfusion and absence of cardiovascular diseases have been frequently proposed as possible mediators [29].

Findings revealed no support for $\mathrm{H}_{\mathrm{A}} 2$ as there was no link found between social networks and cognitive function upon controlling for confounders in the tertiary model. The non-significance found in this study cannot be deciphered, but it could probably be attributed to the way social network is measured and stronger relationships between certain sociodemographic variables (e.g., sex, age, ethnicity, and year(s) of education) with cognitive function. Nonetheless, the positive role of social networks towards cognitive function have been widely presented [30]. The positive relationship can be attributed to positive social networks which buffers stress, offers mental stimulation, and encourages health behaviours [31]. The current study evaluated just the quantitative elements of social networks like the functional and structural attributes of individual social network rather than exploring qualitative aspects of social networks such as perceived adequacy of and feelings related to social relationships. Literature have shown a positive association between qualitative characteristics of social networks with cognitive function among older adults [32]. Future studies should therefore consider measuring qualitative aspects of social networks alongside quantitative aspects.

However, this study was most keen on findings that revealed social networks as a moderator for the link between physical fitness and cognitive function, in the time supporting $\mathrm{H}_{\mathrm{A}} 3$. The study details those individuals with low physical fitness and small social networks showed poorest cognitive function. Therefore, indicating that the negative impact of low physical fitness on cognitive function seems to be more formidable among older adults with limited social networks. Wider old age social networks could reduce the negative impacts of low physical fitness towards cognitive function. A possible reason being larger social networks promote higher wellbeing and/or mental health [33]. Older adults with larger social networks are equipped with family members, relatives, and friends to confide in, especially in times of grave illness and loss, hence encouraging older adults to cope well and remain hopeful. A longitudinal study reported robust relationship between positive wellbeing and cognitive function [34]. Besides, the moderating role of social networks could also be attributed to different behaviours and activities due to different sizes of social networks. Older adults with larger social networks tend to have a healthier lifestyle and be physically active than those with smaller social networks [35], promoting a better 
cognitive function in later life. In other words, social networks have a moderating role in the relationship between physical fitness and cognitive function as a facilitator or inducer of behaviours and activities that promote higher physical fitness resulting in a higher cognitive function. This study also demonstrated that individuals with high levels of physical fitness reported high cognitive function despite small social network size. Therefore, implying that in place of quantitative aspects, qualitative aspects of social networks, such as relationship quality, contact frequency, and emotional closeness is imperative in maintaining cognitive function among older adults with high physical fitness.

The study acknowledges presence of several strengths and limitations. Firstly, the study involved a large and representative sample. Data obtained were representative of different sex, age groups and ethnicity. Thus, findings are generalizable to older adults living in Peninsular Malaysia. Further, the analysis process involved comprehensive control variables which produced reliable results, free from possible confounding effects. However, the study is a cross-sectional study, so causal conclusion is not warranted. Future studies should consider longitudinal data to validate findings from this study. Aside from that, the measure of physical fitness was limited to aerobic endurance. Other aspects of physical fitness, like muscular endurance, muscular strength, flexibility, and body composition were not included. Future studies should consider including the aforementioned aspects when measuring physical fitness. Finally, evaluation of social network was only focused on quantitative measures of social networks. Both quantitative and qualitative aspects of social networks could be a possible resource that promotes cognitive function among physically unfit older adults. Hence, it is suggested that future studies include qualitative aspect of social networks in order to obtain a clearer picture of domains influencing cognitive function among older persons.

\section{Conclusions}

This study presents novel discovery on the moderating mechanism underpinning the relationship between physical fitness and cognitive function among older adults. Findings also adds to the literature elucidating the role of physical fitness and social network in predicting later-life cognitive function. This study found that social networks moderated the relationship between physical fitness and cognitive function as older adults with low levels of physical fitness and small social networks revealed lowest cognitive function. The moderating effects of social networks could be attributed to mental health, behaviours and activities as older adults with larger social networks tend to have better mental health, a healthier lifestyle and be more active. Hence, healthcare practitioners and volunteers are recommended to advance community support or peer-based interventions that encourage social networking among physically unfit community-dwelling older persons to prevent cognitive impairment and promote healthy ageing.

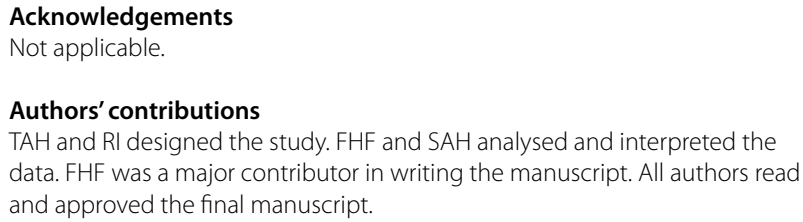

\section{Funding}

The Transforming Cognitive Frailty to Later-Life Self-sufficiency (AGELESS) study is funded by the Ministry of Higher Education Malaysia Long-Term Research Grant Scheme (LRGS/1/2019/UM/01/1/2), which has been evolved from the LRGSTUA Study.

\section{Availability of data and materials}

The datasets used and/or analysed during the current study are available from the corresponding author on reasonable request.

\section{Declarations}

\section{Ethics approval and consent to participate}

The Medical Research Ethics Committee of Faculty of Medicine and Health Sciences, Universiti Putra Malaysia, approved this study's protocol with IRB number: NMRR-13-1023-14660. The participants were provided with an information sheet and the study was explained to them verbally, providing an opportunity for them to discuss any concerns prior to providing written consent. Informed written consent was obtained for all participants before the start of the study. Confidentiality was maintained throughout the study.

\section{Consent for publication}

Not applicable.

\section{Competing interests}

The authors declare that they have no competing interests.

\section{Author details}

${ }^{1}$ Malaysian Research Institute on Ageing (MyAgeing ${ }^{\mathrm{TM}}$ ), Universiti Putra Malaysia, 43400 Serdang, Selangor, Malaysia. ${ }^{2}$ Department of Human Development and Family Studies, Faculty of Human Ecology, Universiti Putra Malaysia, 43400 Serdang, Selangor, Malaysia. ${ }^{3}$ Department of Resource Management and Consumer Studies, Faculty of Human Ecology, Universiti Putra Malaysia, 43400 Serdang, Selangor, Malaysia.

Received: 9 November 2020 Accepted: 10 November 2021

Published online: 07 December 2021

\section{References}

1. Department of Statistics Malaysia. Selected demographic estimates Malaysia 2016: Department of Statistics Malaysia; 2016. https://www. dosm.gov.my/v1/index.php?r=column/cthemeByCat\&cat=397\&bul_id= WVVQUnYrZkRWK1k1QXZMbEpuV1hNUT09\&menu_id=LOpheU43NW JwRWVSZkIWdzQ4TIhUUT09\#. Accessed 9 Aug 2017

2. Department of Statistics Malaysia. Population projections Malaysia 20102014. Malaysia: Department of Statistics; 2012

3. Miyawaki, CE, Liu, M. Gender differences in cognitive impairment among the old and the oldest-old in China. Geriatr Gerontol Int. 2019;19:586-92. https://doi.org/10.1111/ggi.13666.

4. Foong HF, Hamid TA, Ibrahim R, Haron SA. Moderating effect of intrinsic religiosity on the relationship between depression and cognitive 
function among community-dwelling older adults. Aging Ment Health. 2018;22:483-8.

5. Taylor D. Physical activity is medicine for older adults. Postgrad Med J. 2014;90:26-32.

6. Farrell SW, Abramowitz AR, Willis BL, Barlow CE, Weiner M, Falkowski J, et al. The relationship between cardiorespiratory fitness and Montreal cognitive assessment scores in older adults. Gerontology. 2018;64:440-5.

7. Stuckenschneider T, Askew CD, Rüdiger S, Polidori MC, Abeln V, Vogt $T$, et al. Cardiorespiratory fitness and cognitive function are positively related among participants with mild and subjective cognitive impairment. J Alzheimers Dis. 2018;62:1865-75.

8. Zhou J. Improving older people's life satisfaction via social networking site use: evidence from China. Australas J Ageing. 2018;37:E23-8.

9. Lubben J, Blozik E, Gillmann G, lliffe S, Von Kruse WR, Beck JC, et al. Performance of an abbreviated version of the lubben social network scale among three European community-dwelling older adult populations. Gerontologist. 2006;46:503-13.

10. Ibrahim R, Abolfathi Momtaz Y, Hamid TA. Social isolation in older Malaysians: prevalence and risk factors. Psychogeriatrics. 2013;13:71-9.

11. Pillai JA, Verghese J. Social networks and their role in preventing dementia. Indian J Psychiatry. 2009;51(Suppl 1):S22-8.

12. Perry BL, McConnell W, Finley E, Duran T, Pescosolido B, Unverzagt FW, et al. Social networks and cognitive performance in older adults with normal cognition, mild cognitive impairment, and mild Alzheimer's disease. Alzheimers Dement. 2017;13:505-6.

13. Marioni RE, Proust-Lima C, Amieva H, Brayne C, Matthews FE, Dartigues JF, et al. Social activity, cognitive decline and dementia risk: a 20-year prospective cohort study chronic disease epidemiology. BMC Public Health. 2015;15:1089

14. Schrempft S, Jackowska M, Hamer M, Steptoe A. Associations between social isolation, loneliness, and objective physical activity in older men and women. BMC Public Health. 2019;19:74.

15. McPhee JS, French DP, Jackson D, Nazroo J, Pendleton N, Degens H. Physical activity in older age: perspectives for healthy ageing and frailty. Biogerontology. 2016;17:567-80.

16. Cornwell B, Schumm LP, Laumann EO. The social connectedness of older adults: a national profile. Am Sociol Rev. 2008;73:185-203.

17. Shahar S, Omar A, Vanoh D, Hamid TA, Mukari SZM, Din NC, et al. Approaches in methodology for population-based longitudinal study on neuroprotective model for healthy longevity (TUA) among Malaysian older adults. Aging Clin Exp Res. 2016;28:1089-104.

18. Foong HF, Hamid TA, Ibrahim R, Haron SA. Mediating role of neuroticism in the association between loneliness and cognitive function among community-dwelling older adults. Australas J Ageing. 2018;37:283-7.

19. Ibrahim NM, Shohaimi S, Chong HT, Rahman AHA, Razali R, Esther E, et al. Validation study of the mini-mental state examination in a Malayspeaking elderly population in Malaysia. Dement Geriatr Cogn Disord. 2009;27:247-53.

20. Folstein MF, Folstein SE, McHugh PR. "Mini-mental state". A practical method for grading the cognitive state of patients for the clinician. J Psychiatr Res. 1975;12:189-98.

21. Rikli RE, Jones CJ. Functional fitness normative scores for communityresiding older adults, ages 60-94. J Aging Phys Act. 1999;7:160-79.
22. Haas F, Sweeney G, Pierre A, Plusch T, Whiteson J. Validation of a 2 minute step test for assessing functional improvement. Open J Ther Rehabil. 2017;5:71-81.

23. O'Brien RM. A caution regarding rules of thumb for variance inflation factors. Qual Quant. 2007:41:673-90.

24. Foong HF, Hamid TA, Ibrahim R, Haron SA, Shahar S. Predicting cognitive function of the Malaysian elderly: a structural equation modelling approach. Aging Ment Health. 2018;22:109-20. https://doi.org/10.1080/ 13607863.2016 .1231172

25. Freudenberger P, Petrovic K, Sen A, Töglhofer AM, Fixa A, Hofer E, et al. Fitness and cognition in the elderly: the Austrian stroke prevention study. Neurology. 2016;86:418-24

26. Wu ZJ, Wang ZY, Hu BQ, Zhang $X H$, Zhang F, Wang $H L$, et al. Relationships of accelerometer-based measured objective physical activity and sedentary behaviour with cognitive function: a comparative cross-sectional study of China's elderly population. BMC Geriatr. 2020;20:149.

27. Ingold M, Tulliani N, Chan CCH, Liu KPY. Cognitive function of older adults engaging in physical activity. BMC Geriatr. 2020;20:229. https://doi.org/10 1186/s12877-020-01620-w.

28. Daimiel L, Martínez-González MA, Corella D, Salas-Salvadó J, Schröder $\mathrm{H}$, Vioque J, et al. Physical fitness and physical activity association with cognitive function and quality of life: baseline cross-sectional analysis of the PREDIMED-Plus trial. Sci Rep. 2020;10:3472.

29. Busse AL, Gil G, Santarém JM, Jacob Filho W. Physical activity and cognition in the elderly: a review. Dement Neuropsychol. 2009;3:204-8.

30. Kelly ME, Duff H, Kelly S, McHugh Power JE, Brennan S, Lawlor BA, et al. The impact ofsocial activities, social networks, social support and social relationships on the cognitive functioning of healthy older adults: a systematic review. Syst Rev. 2017;6:259.

31. Ozbay F, Johnson DC, Dimoulas E, Morgan CA, Charney D, Southwick S. Social support and resilience to stress: from neurobiology to clinical practice. Psychiatry (Edgmont). 2007:4:35-40.

32. Li $M$, Dong $X$. Is social network a protective factor for cognitive impairment in US Chinese older adults? Findings from the PINE study. Gerontology. 2018;64:246-56.

33. Park NS, Jang Y, Lee BS, Chiriboga DA, Chang S, Kim SY. Associations of a social network typology with physical and mental health risks among older adults in South Korea. Aging Ment Health. 2018;22:631-8.

34. Allerhand M, Gale CR, Deary IJ. The dynamic relationship between cognitive function and positive well-being in older people: a prospective study using the English longitudinal study of aging. Psychol Aging. 2014:29:306-18.

35. Chen W-L, Zhang C-G, Cui Z-Y, Wang J-Y, Zhao J, Wang J-W, et al. The impact of social capital on physical activity and nutrition in China: the mediating effect of health literacy. BMC Public Health. 2019;19:1713.

\section{Publisher's Note}

Springer Nature remains neutral with regard to jurisdictional claims in published maps and institutional affiliations.

Ready to submit your research? Choose BMC and benefit from

- fast, convenient online submission

- thorough peer review by experienced researchers in your field

- rapid publication on acceptance

- support for research data, including large and complex data types

- gold Open Access which fosters wider collaboration and increased citations

- maximum visibility for your research: over $100 \mathrm{M}$ website views per year

At BMC, research is always in progress.

Learn more biomedcentral.com/submissions 